\title{
Transcriptional analysis of the recA gene of Streptococcus thermophilus

\author{
Gabriele Giliberti ${ }^{1,2}$, Loredana Baccigalupi ${ }^{1}$, Angelina Cordone ${ }^{1}$, Ezio Ricca1 \\ and Maurilio De Felice*1
}

\author{
Address: ${ }^{1}$ Dipartimento di Biologia Strutturale e Funzionale, Università Federico II, Napoli, Italy and ${ }^{2}$ Dipartimento di Scienze e Tecnologie \\ Biomediche, Università di Cagliari, Cittadella Universitaria, 09042 Monserrato, Cagliari, Italy \\ Email: Gabriele Giliberti - gabrielegiliberti@microbiologia.ca.it; Loredana Baccigalupi - lorbacci@unina.it; \\ Angelina Cordone - acordone@unina.it; Ezio Ricca - ericca@unina.it; Maurilio De Felice* - defelice@unina.it \\ * Corresponding author
}

Published: 14 September 2006

Microbial Cell Factories 2006, 5:29 doi:10.1 186/1475-2859-5-29
Received: 23 December 2005

Accepted: 14 September 2006

This article is available from: http://www.microbialcellfactories.com/content/5/I/29

(C) 2006 Giliberti et al; licensee BioMed Central Ltd.

This is an Open Access article distributed under the terms of the Creative Commons Attribution License (http://creativecommons.org/licenses/by/2.0), which permits unrestricted use, distribution, and reproduction in any medium, provided the original work is properly cited.

\begin{abstract}
Background: RecA is a highly conserved prokaryotic protein that not only plays several important roles connected to DNA metabolism but also affects the cell response to various stress conditions. While RecA is highly conserved, the mechanism of transcriptional regulation of its structural gene is less conserved. In Escherichia coli the LexA protein acts as a recA repressor and is able, in response to DNA damage, of RecA-promoted self-cleavage, thus allowing recA transcription. The LexA paradigm, although confirmed in a wide number of cases, is not universally valid. In some cases LexA does not control recA transcription while in other RecA-containing bacteria a LexA homologue is not present.

Results: We have studied the recA transcriptional regulation in $\mathrm{S}$. thermophilus, a bacterium that does not contain a LexA homologue. We have characterized the promoter region of the gene and observed that its expression is strongly induced by DNA damage. The analysis of deletion mutants and of translational gene fusions showed that a DNA region of 83 base pairs, containg the recA promoter and the transcriptional start site, is sufficient to ensure normal expression of the gene. Unlike LexA of $E$. coli, the factor controlling recA expression in S. thermophilus acts in a RecAindependent way since recA induction was observed in a strain carrying a recA null mutation.

Conclusion: In S. thermophilus, as in many other bacteria,recA expression is strongly induced by DNA damage, however, in this organism expression of the gene is controlled by a factor different from those well characterized in other bacteria. A small DNA region extending from 62 base pairs upstream of the $r e c A$ transcriptional start site to 21 base pairs downstream of it carries all the information needed for normal regulation of the $S$. thermophilus recA gene.
\end{abstract}

\section{Background}

The bacterial RecA protein has an important role in a variety of cellular processes, such as the control of DNA status, repair of stalled replication forks, double-strand break repair, general recombination, induction of the SOS response and induction of temperate phages [1]. RecA has also been recently shown to possess other roles related to DNA metabolism, such as the apparent motor function in 
which DNA strand exchange is coupled to ATP hydrolysis [2]. In addition, roles of RecA in degradation of pectin in Erwinia carotovora [3], expression of adherence factors in Vibrio cholerae [4], pilus phase transition in Neisseria gonorrhoeae [5] and switching from pathogenic smooth to non-pathogenic rough cell form in Pseudomonas tolaasii [6], have been proposed and explained as secondary effects of RecA action on DNA structure and function.

However, RecA has been also associated to phenomena apparently not related to DNA metabolism, such as the adaptation of Lactococcus lactis to oxygen and heat shock $[7,8]$ and of Bacillus subtilis to nutrient starvation [9]. Also in the moderately thermophilic lactic acid bacterium Streptococcus thermophilus recA expression is involved in the stress response mechanism [10]. S. thermophilus is a commercially important bacteria since it is used, along with Lactobacillus spp., as a starter culture for the manufacture of several fermented dairy foods. Its industrial use has substantially increased during the past two decades, as a result of the strong increase in consumption of dairy products. Such increase has led, as a consequence, to new demands on $S$. thermophilus performances, as stabile fermentation properties, consistent flavor and texture characteristics, resistance to bacteriophage infections. Research during the past two decades on the physiology of $S$. thermophilus has revealed important information on some of these properties, and more recently genome data have become publicly available [11]. Analysis of the $S$. thermophilus genome revealed a small size $(1.8 \mathrm{Mb}$, probably the smallest genome of all lactic acid bacteria), a low $\mathrm{G}+\mathrm{C}$ ratio $(40 \%)$ and a phylogenetical relationship to mesophilic lactococci [12]. A recA insertional mutant of $S$. thermophilus, in addition to typical recA phenotypes (reduced growth rate and sensitivity to mitomycin Cinduced DNA damages) also showed a strong reduction of viability and the appearance of a sub-population of morphologically altered cells in response to both heat shock and nutrient starvation [10]. These effects were independent from ClpL and GroEL homologues that were normally induced in the recA null mutant [10].

The transcriptional regulation of the recA gene has been studied in a variety of different bacteria. In E. coli, as well as in several other organisms, under physiological conditions recA transcription is repressed by the LexA protein that binds to its consensus binding site located in the promoter region of recA $[13,14]$. Upon DNA damage, RecA binds to single-stranded DNA regions generated by replication blocks, originating a nucleoprotein filament $\left(\right.$ RecA $\left.^{*}\right)$ [15]. Activated RecA* possesses co-protease activity [15], required for self-cleavage of LexA [16]. The RecA*-promoted self-cleavage of LexA results in the inactivation of the repressor and thus in the induction of the SOS regulon including the recA gene [16]. In vitro experi- ments have shown that in the absence of RecA*, LexA is cleaved at high $\mathrm{pH}$ demonstrating that the protein is able to perform self-cleavage [17].

In the gram-positive model organism Bacillus subtilis, a LexA homologue is present and the recA gene is regulated with a mechanism similar to that studied in $E$. coli. The $E$. coli LexA and its $B$. subtilis homologue share a $52 \%$ similarity that becomes lower in the helix-turn-helix domain. As a consequence, the two proteins recognize different DNA target sites (5'-CTGTN ${ }_{8}$ ACAG-3' for E. coli and 5'-

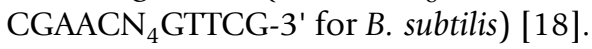

In other bacteria different mechanisms of transcriptional regulation for the recA gene have been proposed. Myxococcus xanthus and Deinococcus radiodurans, although not similar to each other, both contain RecA and LexA homologues and control recA transcription with mechanisms that differ from the E. coli paradigm $[19,20]$.

In L. lactis while a highly conserved RecA homologue is present [7] a LexA homologue has not been found. In this organism a different protein, HdiR, not homologous to LexA, has been shown to regulate several genes of the SOS system but not recA [8]. These evidence therefore suggest that while the RecA is highly conserved in prokaryotes, the mechanism of transcriptional regulation of its structural gene is less conserved.

We analyze here the expression of the recA gene of $S$. thermophilus and report evidence that recA expression and DNA damage-induction are exerted in a RecA-independent fashion through a factor not homologous to those well characterized in other bacteria.

\section{Results and discussion \\ Mapping of the 5 ' terminus of the recA gene}

Primer extension experiments were carried out to map the 5 ' terminus of recA mRNA. Two radioactively labelled synthetic primers, designated A3 and A4 (Methods) and annealing the proximal part of $r e c A$ mRNA (Fig. 1A), were used to hybridize $S$. thermophilus total RNA. Since it had been previously reported $[3,21,22]$ that in several bacteria $r e c A$ is expressed at a very low basal level and is transcriptionally induced by mitomycin C, we used total RNA from exponentially growing cells of $S$. thermophilus before and after exposure to sublethal concentration $(20 \mathrm{ng} / \mathrm{ml})$ of mitomycin C [10]. Reverse transcriptase was then used to generate cDNA primer extension products, which were separated by $6 \%$ polyacrilamide gel electrophoresis together with dideoxy sequencing ladders generated by using A3 and A4 primers and cloned recA DNA as a template. The results obtained with the $\mathrm{A} 3$ primer (Fig. 1B) were in agreement with the results obtained with the A4 primer (data not shown). The extension product obtained 
A

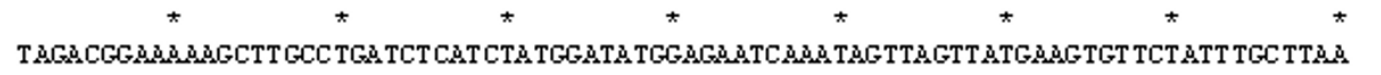

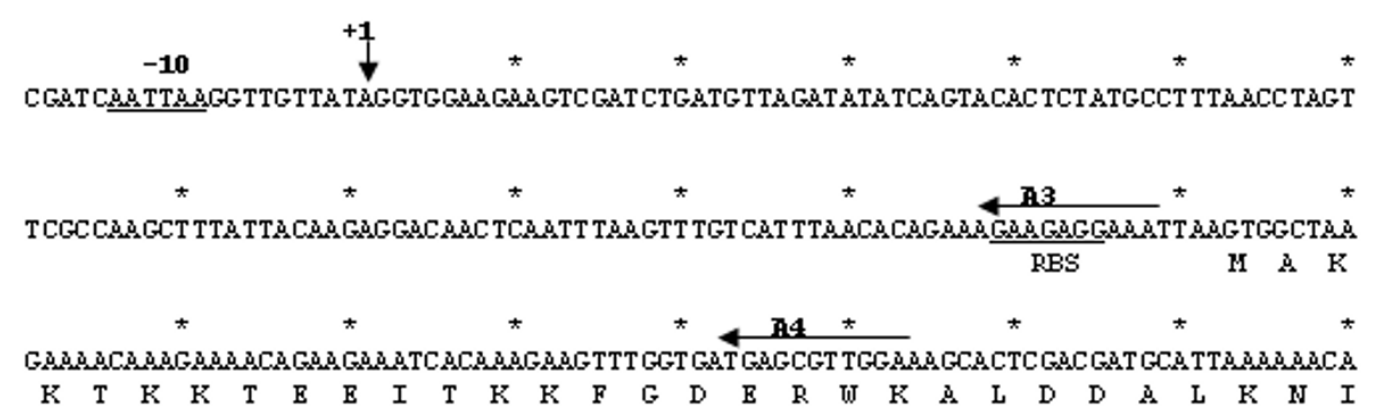

\section{B}

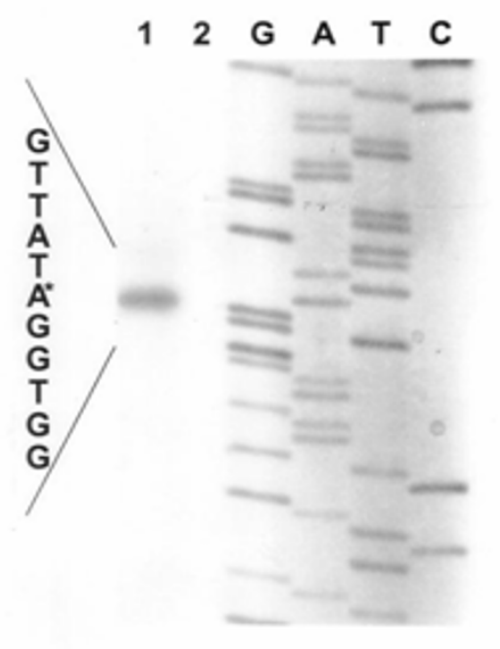

\section{Figure I}

The recA promoter region of $S$. thermophilus. (A) Nucleotide sequence of the recA promoter region of $S$. thermophilus. Deduced amino acid sequence of the $30 \mathrm{~N}$-terminal residues of RecA is also reported. Horizontal and vertical arrows indicate synthetic oligonucleotide used in the primer extension analysis and the transcriptional start point. Regions of homology with the -10 and -35 consensus sequences are underlined. (B) Primer extension analysis performed with total RNA extracted from exponentially growing cells of $S$. thermophilus before (lane 2 ) and after (lane I) exposure to sublethal concentration (20 ng/ml) of mitomycin C [10]. Primer extension and sequencing reactions were primed with the synthetic oligonucleotide A3. Similar results were obtained with oligonucleotide $A 4$ (data not shown). 
allowed us to localize the 5' terminus of recA mRNA 132 bp upstream of the beginning of the ORF. The extension product was found only when recA expression was induced with mitomycin $\mathrm{C}$, suggesting that in $S$. thermophilus recA expression is strictly regulated. Sequences upstream of the 5 ' terminus (+1) resembled the conserved features of a typical promoter of an E. coli housekeeping gene, matching in three of six positions the consensus -10 and in four of six positions the consensus -35 (Fig. 1A).

recA expression is induced by mitomycin $C$ but not by heat shock or nutrient starvation

To analyze the expression of the recA gene we constructed a recA::gusA translational fusion. A 609 bp DNA fragment containing the recA promoter region and codons for $18 \mathrm{~N}$ terminal amino acid residues of the recA ORF was amplified from $S$. thermophilus chromosomal DNA by using oligonucleotides P1 and P5 as primers (Methods). The PCR product was then fused in frame to the gusA gene of $E$. coli carried by plasmid pGU0, previously obtained by inserting the gusA coding region in the EcoRI site of the commercial plasmid pGemT-easy (Promega). The recombinant plasmid obtained, pGU1, was then used as a template for DNA sequencing reactions performed to verify that the recA and gusA genes were fused in frame (not shown).

The gene fusion was then transferred into the E. coli - S. thermophilus shuttle vector pNZ124, yielding plasmid pNG1 that was used to transform competent cells of the $S$. thermophilus strain Sfi39. The recombinant strain, S1, was grown at $42^{\circ} \mathrm{C}$ anaerobically in the presence and in the absence of a sublethal concentration $(200 \mathrm{ng} / \mathrm{ml})$ of mitomycin C [10] and exponentially growing cells collected by centrifugation and assayed for $\beta$-glucuronidase activity (Methods). Although the conditions of mitomycin induction differed substantially between the primer extension of Fig. $1 \mathrm{~B}(20 \mathrm{ng} / \mathrm{ml})$ and the $\beta$-glucuronidase assay of Fig. $2(200 \mathrm{ng} / \mathrm{ml})$ the two experiments together indicated that $r e c A$ is poorly expressed in uninduced conditions and is strongly induced by mitomycin addition to the growth medium.

Since $r e c A$ expression is involved in the cell response to heat shock and nutrient starvation [10], we decided to verify whether these stress conditions affected recA expression. Strain S1 was then grown at $42^{\circ} \mathrm{C}$ anaerobically to mid exponential phase and shifted at $50^{\circ} \mathrm{C}$ for three hours as previously reported [10]. A parallel culture was grown at $42^{\circ} \mathrm{C}$ for 48 hours to induce nutrient starvation, as previously reported [10]. Cell samples were collected and assayed for $\beta$-glucuronidase activity (Methods). In both stress conditions, the recA-driven $\beta$-glucuronidase activity was similar to that measured in exponentially growing cells not exposed to heat shock or nutrient starva- tion, thus indicating that both conditions do not affect recA expression (Fig. 2).

Results obtained with the primer extension experiment of Fig. 1 together with the analysis of the recA-driven $\beta$-glucuronidase activity of Fig. 2, suggest that expression of the recA gene is transcriptionally controlled and is inducible by DNA damages, caused in laboratory conditions by the presence of mitomycin $\mathrm{C}$ in the growth medium [10].

\section{Activation of recA expression is not RecA-dependent}

A computer-assisted analysis of the recently released $S$. thermophilus genome [11] failed to reveal homologues of the E. coli or Bacillus subtilis LexA proteins (not shown). This analysis, however, identified in the $S$. thermophilus genome a homologue (YP_139374) of the HdiR protein that in L. lactis acts as transcriptional regulator of various SOS genes [8]. Although HdiR does not control the expression of recA in L. lactis [8], we searched for the HdiR putative consensus sequence (5'-tttATCAGtTtttCTGATaaa-3') [8] in the recA promoter region of S. thermophilus. Since no sequences matching the putative consensus for HdiR binding were found and since HdiR is not involved in $r e c A$ regulation in the phylogenetically related $L$. lactis, it is likely that the protein controlling recA expression in S. thermophilus is not the HdiR homologue, YP_139374. Additional support for this conclusion comes also from the observation that HdiR acts in L. lactis in a RecAdependent way [8] while the $S$. thermophilus factor is RecAindependent (see below).

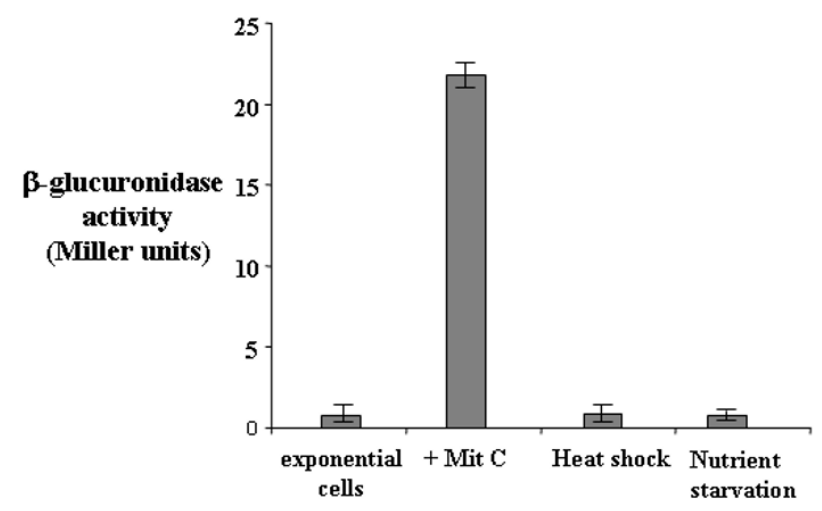

Figure 2

recA-driven $\beta$-glucuronidaseactivity. Levels of $\beta$-glucuronidase activity in $S$. thermophilus strain Sfi39 containing the translational recA::gusA. Samples were harvested from exponentially growing cells, from exponential cells exposed to a sublethal concentration $(200 \mathrm{ng} / \mathrm{ml})$ of mitomycin C [10] or to heat-shock or nutrient starvation. Data are the average of three independent experiments. 
Since in LexA-containing bacteria DNA damage-induction is RecA-promoted $[15,16]$, we decided to verify whether in $S$. thermophilus such induction, although mediated by a different protein, was still under RecA control. To evaluate recA expression in a wild type and a $r e c A$ null mutant we performed RT-PCR experiments with the synthetic primers, A4 and A5 (Methods). Total RNA was extracted from exponentially growing cells of the wild type and the recA null mutant strain before and after exposure to sublethal concentration $(20 \mathrm{ng} / \mathrm{ml})$ of mitomycin C [10] and measured spectrophotometrically. One-step reverse transcription-PCR (RT-PCR) were carried out by using a Access RTPCR Kit (Promega). PCR products were analyzed by electrophoresis on a $2 \%$ agarose gel and the linearity of the reactions tested amplifying the 16S RNA gene by using various amounts of RNA for each sample as templates. Equal amounts of RNA were then used as templates in RTPCR reactions to amplify the recA gene. As reported in Fig. 3 , recA transcription was induced by sublethal concentration $(20 \mathrm{ng} / \mathrm{ml})$ of mitomycin C in both the wild type and the recA mutant strain. The induction conditions used for the experiment of Fig. 3 were identical to those used for the primer extension of Fig. $1 \mathrm{~B}$ and the observation that a basal level of expression can be seen in Fig. 3 but not in Fig. 1B is most likely due to the higher sensitivity of the PCR-based approach.

These results indicate that the mitomycin-mediated induction of recA expression is controlled in $S$. ther- mophilus by a mechanism not requiring RecA, and thus different from those so far described in other bacteria.

\section{Minimal DNA region needed for recA repression and induction}

To study the mechanism controlling recA expression in $S$. thermophilus in more details we performed a deletion analysis of the recA promoter region. We started our analysis from plasmid pNG1, containing 417 bp upstream and 191 bp downstream of the recA transcriptional start site, and sufficient to ensure regulation and strong induction of the gene (Fig. 2). Similarly to what described for the construction of plasmid pNG1, a PCR-based strategy was followed to obtain plasmids in which the 609 bp insert of pNG1 was shortened at its $5^{\prime}$ end of 89 (pNG2), 301 (pNG3) and 355 (pNG4) bp (Fig. 4). All plasmids were independently used to transform competent cells of the $S$. thermophilus strain Sfi39. Recombinant strains S1 (pNG1), S2 (pNG2), S3 (pNG3) and S4 (pNG4), were all grown anaerobically at $42^{\circ} \mathrm{C}$ and exponential cells collected and assayed for $\beta$-glucuronidase activity. As shown in Fig. 4, similar levels of $\beta$-glucuronidase activity were observed in all strains grown in the presence or in the absence of mitomycin C $(200 \mathrm{ng} / \mathrm{ml})$. These results therefore indicated that DNA carried by plasmid pNG4 contains all signals needed for the transcriptional regulation of the gene.

As determined with the primer extention of Fig. 1, the $S$. thermophilus recA gene has a 132 bp DNA region that is
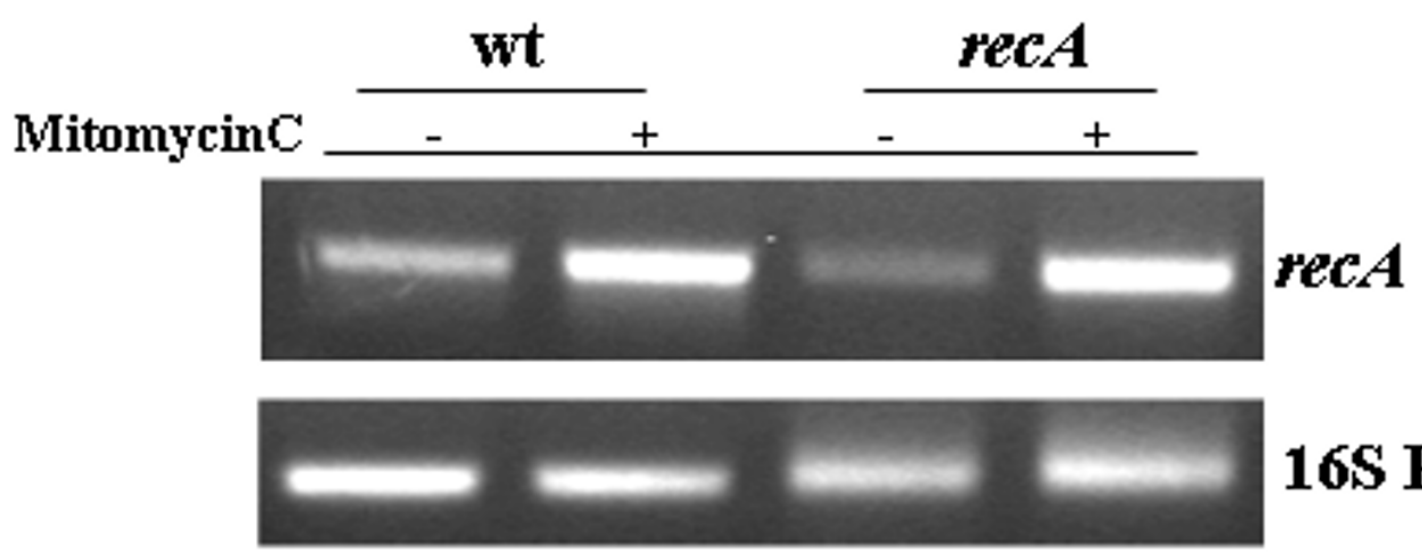

\section{S RNA}

\section{Figure 3}

Effects of RecA on recA transcription. RT-PCR analysis performed on total RNA extracted from a wild type and a congenic strain containing a recA null mutation [10]. RNA was extracted from exponentially growing cells before or after exposure to sublethal concentration $(20 \mathrm{ng} / \mathrm{ml})$ of mitomycin C [10]. The I6S RNA gene was used as a standard to calibrate the amount of RNA to be used with synthetic oligonucleotides amplifying the recA gene. 


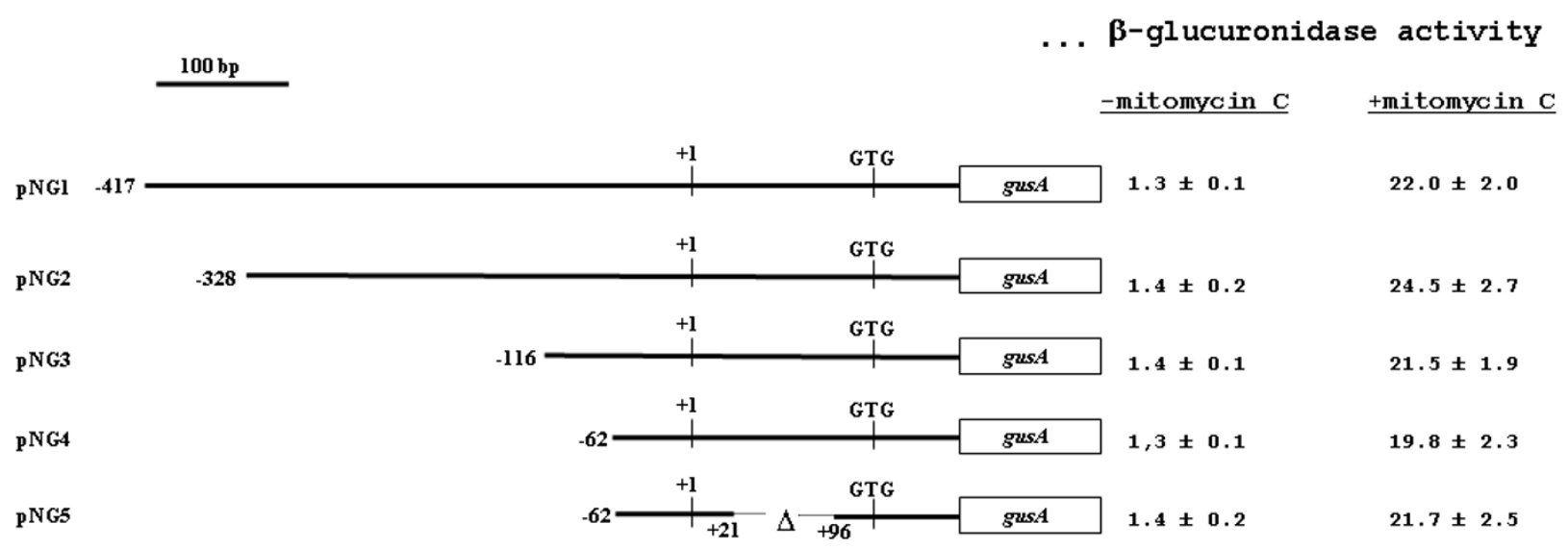

\section{Figure 4}

Deletion analysis of the recA regulatoryregion. The various plasmids carrying the recA promoter region translationally fused to the gusA gene and the $\beta$-glucuronidase activities obtained from cells containing those plasmids grown without and with sublethal concentration $(200 \mathrm{ng} / \mathrm{ml})$ of mitomycin C [10] are reported. For each plasmid transcriptional and translational start points are indicated. The extension of $S$. thermophilus DNA carried by each plasmid is indicated referring to the transcriptional start point as $+\mathrm{I}$. Enzymatic data are the average of three independent experiments.

transcribed but not translated. To verify whether this region, present in plasmid $\mathrm{pNG} 4$, contains transcriptional signals we constructed plasmid pNG5 (Methods), carrying a 75 bp deletion within the 132 bp untranslated region (Fig. 4). Strain S5, carrying plasmid pNG5, was then assayed in parallel with strains S1, S2, S3 and S4 and showed similar levels of $\beta$-glucuronidase activity both in the absence and in the presence of the inducer mitomycin C (Fig. 4).

Our deletion analysis indicate that a DNA fragment of 83 bp, extending from 62 bp upstream and 21 bp downstream of the transcriptional start site, has all the information for regulation and full induction of the recA gene.

\section{Conclusion}

1) We have characterized the recA promoter region of $S$. thermophilus and observed that expression of the gene is strictly regulated and induced by DNA damages.

2) Although RecA is required for $S$. thermophilus response to heat shock and nutrient starvation, expression of its structural gene is not affected by either stress condition.

3) Although functionally homologous to the LexA protein of other bacteria, the $S$. thermophilus protein controlling recA expression is not a structural homolog of LexA.

4) Unlike LexA of E. coli, the S. thermophilus protein controlling recA expression acts in a RecA-independent fashion.
5) An 83 bp DNA fragment containing the recA promoter and extending from $62 \mathrm{bp}$ upstream to $21 \mathrm{bp}$ downstream of the transcriptional start site, has all signals for regulation of the gene.

\section{Methods}

\section{Bacterial strains, growth conditions and bacterial transformation}

Strains used were S. thermophilus Sfi39 [23] and E. coli $\mathrm{DH} 5 \alpha$ [24]. S. thermophilus was grown in anaerobic conditions in either HJL liquid medium or LM17 (lactose supplemented M17) solid medium [25]. The E. coli strain was grown aerobically in LB medium [24].

S. thermophilus and E. coli cells were transformed with plasmid DNA as previously described by electroporation [10] and by $\mathrm{CaCl}_{2}$-treatment [23], respectively.

\section{Primer extension analysis}

Total RNA was extracted from exponentially growing cells before and after exposure to $20 \mathrm{ng} / \mathrm{ml}$ mitomycin C, by use of the RNeasy kit (QIAGEN). $50 \mu \mathrm{g}$ of total RNA were used with $\gamma^{32}$ PdATP (NEN) labeled oligonucleotides (A3: 5'-CCTCTTCTTTCTGTG-3' and A4: 5'-CAACGCTCATCACCAA-3'), dNTP and AMV Reverse transcriptase (BRL) to prime cDNA synthesis, as previously described [26]. Reaction products were fractionated on $8 \mathrm{M}$ urea $-6 \%$ polyacrilamide gels alongside with DNA sequencing reactions primed with the same oligonucleotide. 


\section{Reverse transcription-PCR analysis}

Total RNA was extracted from a wild type and a isogenic strain carrying a recA null mutation before and after 30 min of exposure to $20 \mathrm{ng} / \mathrm{ml}$ of mitomicin C by use of RNeasy kit (Qiagen). Each RNA sample was treated with DNAse turbo (Ambion) following manufacturer instructions and the amount of RNA determined by spectophotometer. Identical amounts of RNA (200 ng) were then used in one-step RT-PCR experiments using ACCESS RTPCR SYSTEM (Promega) and primer sets specific for the recA gene (A4: GGTGGAAGAAGTCGATCTGATG; A5 CCTTGCTCACCAGAATCAGGC) and for the 16S ribosomal gene (16S-for: CCGCAGCTAACGCATTAAGC; 16Srev: GACTCGCAACTCGTTGTACC) used as RNA concentration control. PCRs were carried out with RNA alone to exclude that the amplification products could derive from contaminating genomic DNA.

\section{Plasmid construction}

pGU0 plasmid was obtained by inserting a DNA fragment with EcoRI flanking ends and coding for the gusA gene of E. coli into the pGEMT-easy plasmid (PROMEGA) previously digested with the same restriction enzyme. A 609 bp DNA fragment, containing the recA promoter region (417 nucleotides upstream and 191 downstream transcriptional start site) was PCR amplified using $S$. thermophilus chromosomal DNA as a template and oligonucleotides P1 (5'-GCTTGCTGATCTCATCT-3') and P5 (5'-AAACCATGGCTCATCAT CACCAAACTTC-3') as primers. The PCR fragment was digested with the NotI restriction enzyme and cloned into pGU0, previously digested with the same enzyme, yielding plasmid pGU1.

The recA::gusA translational fusion was then moved by using SacI and SphI/NspI restriction sites, in the pNZ124 vector, able to produce a RepA protein and, as a consequence, to replicate in $S$. thermophilus. The resulting plasmid, pNG1, was then used to transform competent cells of $S$. thermophilus strain Sfi39.

An identical strategy was followed to obtain plasmids pNG2, pNG3, pNG4 (containing respectively 328, 116 and 62 nucleotides upstream of the transcriptional start site) by pairing with primer P5 primers: P2 (5'CTGCAGCTGAAAGTTTAACAGCTGG-3'), P3 (5'-GTGATTACGGAATTGCGCTTACTGGAGTAG-3') and P4 (5'GCAGGTACAGTCTTTATTGG-3'), respectively.

Plasmid pNG5 was obtained by performing PCR reactions on pNG4 DNA as a template and oligonucleotides SMF1 (5'-AAACTCCCGGGTCAGATCGACTTCTTCCACC-3'; underlined is a SmaI site)-SM1 (5'-AAAATTTTCCAGCGCTACCGCTCG-3') and SMF2 (5'-TCTGACCCGGGAGTTTGTCATTTAACACAG-3'; underlined is a SmaI site)-SM2 (5'-CACCAACGCTGATCAATTCCACAG-3') as primer pairs. Amplified fragments were independently cloned into pGEM-Teasy vectors and the recombinant plasmids double digested with SmaI (inserted with oligonucleotides SMF1 and SMF2) and ScaI (present in pGEMTeasy). Released DNA fragments of 1.564 and $2.090 \mathrm{bp}$ were then ligated to produce an intermediate vector carrying the recA fragment of plasmid pNG4 with an internal deletion. This fragment was then used to replace the wild type recA sequence of pNG4 by double digestion with Aor $51 \mathrm{HI}$ and AvaII restriction enzymes.

\section{$\beta$-glucuronidase assays}

$\beta$-glucuronidase assays were performed as previously described [27]. For each sample a graph of $A_{405}$ (Y-axis) versus time in minutes (X-axis) was designed; the slope $S$ of the graph in $A_{405}$ units per minute was estimated and units of activity (nanomoles of $p$-nitrophenyl glucuronide hydrolysed per minute) were calculated from $S / \mathrm{V}_{e} \times 0.02$; where $\mathrm{V}_{e}$ is the volume of permeabilized cells in $\mathrm{ml}$ and 0.02 represents $A_{405}$ given relative to $1 \mathrm{nmol}$ of product produced. Specific activity equals units per $A_{590}$. Values reported here were the average of at least three independent experiments. Statistical significance was determined by Student's $t$ test and the significance level was set at $P<$ 0.05 .

\section{Competing interests}

The author(s) declare that they have no competing interests.

\section{Authors' contributions}

GG performed most of the experiments; LB performed the RT-PCR analysis of Fig. 3; AC contributed to plasmids construction and enzymatic assays; ER contributed to experiment design and discussion; MDF contributed discussions and suggestions during the work and helped in the preparation of the manuscript. All authors read and approved the final manuscript.

\section{Acknowledgements}

We thank L. Di lorio for technical assistance. This work was partially supported by Centro Regionale di Competenza BioTekNet, Naples, Italy.

\section{References}

I. Lusetti SL, Cox MM: The bacterial RecA protein and the recombinational DNA repair of stalled replication forks. Annu Rev Biochem 2002, 71:71-100.

2. Cox MM: The bacterial RecA protein as a motor protein. Annu Rev Microbiol 2003, 57:55 I-577.

3. McEvoy JL, Murata H, Chatterjee AK: Genetic evidence foran activator required for induction of pectin lyase in Erwinia carotovora sbsp. carotovora by DNA-damaging agents. J Bacteriol 1992, I 74:547|-5474.

4. Kumar KK, Srivastava R, Sinha VB, Michalski J, Kaper JB, Srivastava BS: recA mutations reduce adherence and colonization byclassical and EI Tor strains of Vibrio cholerae. Microbiol 1994, 140:1217-1222.

5. Koomey M, Gotschlich EC, Robbins K, Bergstrom S, Swanson J: Effects of recA mutations on pilus antigenicvariation and 
phase transition in Neisseria gonorroheae. Genetics 1987, I I 7:391-398.

6. Sinha $\mathrm{H}$, Pain $\mathrm{A}$, Johnstone $\mathrm{K}$ : Analysis of the role of recA in phenotypic switching of Pseudomonas tolaasii. J Bacteriol 2000, 182:6532-6535.

7. Duwat P, Ehrlich SD, Gruss A: The recA gene of Lactococcus lactis: characterization and involvement in oxidative and thermal stress. Mol Microbiol 1995, 17: I I2I-II3I.

8. Savijoki K, Ingmer H, Frees D, Vogensen FK, Palva A, Varmanen P: Heat and DNA damage induction of the LexA-like regulator HdiR from Lactococcus lactis is mediated by RecA and ClpP. Mol Microbiol 2003, 50:609-62I.

9. Sciocchetti SA, Blakely GW, Piggot PJ: Growth phase variation in cell and nucleoid morphology in a Bacillus subtilis recA mutant. J Bacteriol 200I, 183:2963-2968.

10. Giliberti G, Naclerio G, Martirani L, Ricca E, De Felice M: Alteration of cell morphology and viability in a recA mutant of Streptococcus thermophilus upon induction of heat shock and nutrient starvation. Gene 2002, 295: I-6.

II. [http://www.biol.ucl.ac.be/gene/genome/].

12. Hols P, Hancy F, Fontaine L, Grossiord B, Prozzi D, Leblond-Bourget N, Decaris B, Bolotin A, Delorme C, Dusko Ehrlich S, Guedon E, Monnet $\mathrm{V}$, Renault $\mathrm{P}$, Kleerebezem M: New insights in the molecular biology and physiology of Streptococcus thermophilus revealed by comparative genomics. FEMS Microbiol Rev 2005, 29:435-463.

13. Fernandez de Henestrosa AR, Ogi T, Aoyagi S, Chafin D, Hayes JJ, Ohmori $\mathrm{H}$, Woodgate $\mathrm{R}$ : Identification of additional genes belonging to the LexA regulon in Escherichia coli . Mol Microbiol 2000, 35: I560-1572.

14. Courcelle J, Khodursky A, Peter B, Brown PO, Hanawalt PC: Comparative gene expression pro-files following UV exposure in wt and SOS-deficient Escherichia coli . Genetics 200I, I 58:4I-64.

15. Kowalczykowski SC, Dixon DA, Eggleston AK, Lauder S, Rehrauer WM: Biochemistry of homologous recombination in Escherichia coli. Microbiol Rev 1994, 58:401-465.

16. Kim B, Little JW: LexA and lambda Cl repressors as enzymes, specific cleavage in an intermolecular reaction. Cell 1993, 73:1165-1173.

17. Smith MH, Cavenagh MM, Little JW: Mutant LexA proteins with an increased rate of in vivo cleavage. Proc Natl Acad Sci USA I99|, 88:7356-7360

18. Winterling KW, Chafin D, Hayes J], Levine AS, Yasbin RE, Woodgate $R$ : The Bacillus subtilis DinR binding site:redefinition of the consensus sequence. | Bacteriol 1998, I80:220I-22II.

19. Campoy S, Fontes M, Padmanabham S, Cortes P, Montserrat L, Barbè $\mathrm{J}$ : LexA-independent DNA damage-mediated induction of gene expression in Myxococcus xanthus. Mol Microbiol 2003, 49:769-78I.

20. Narumi I, Satoh K, Kikushi M, Funayama T, Yanagisawa T, Kobayashi $Y$, Watanabe $H$, Yamamoto K: The LexA protein from Deinococcus radiodurans is not involved in RecA induction following gamma irradiation. I Bacteriol 200 I, 183:695 I-6956.

21. Giacomoni PU: Survival and induction of recA protein in mitomycin C-treated Escherichia coli rec, lex, or uvr strains. J Biol Chem 1983, 258:13653-13657.

22. Mongkolsuk S, Rabibhadana S, Sukchavalit R, Vaughn G: Construction and physiological analysis of a Xanthomonas oryzae recA mutant. FEMS Microbiol Lett 1998, 169:269-275.

23. Lemoine J, Chirat F, Wieruszelski JM, Strecker G, Favre N, Neeser JR: Structural characterization of the exocellular polysaccharide produced by Streptococcus thermophilus Sfi39 and Sfi I 2. Appl Environ Microbiol 1997, 63:3512-3518.

24. Sambrook J, Fritsch EF, Maniatis T: Molecular cloning. A laboratory manual. Second edition. Cold Spring Harbor Laboratory Press; 1989.

25. Stingele F, Mollet B: Disruption of the gene encoding penicillinbinding protein $2 b(p b p 2 b)$ cause altered cell morphology and cease in exopolysaccharide production in Streptococcus thermophilus Sfi6. Mol Microbiol 1996, 22:357-366.

26. Limauro D, Falciatore A, Basso AL, Forlani G, De Felice M: Proline biosynthesis in Streptococcus thermophilus : characterization of the proBA operon and its products. Microbiol 1996, 142:3275-3282.
27. Cordone A, Mauriello EMF, Pickard D, Dougan G, De Felice M, Ricca E: The Irp Gene and Its Role in Type I Fimbration in Citrobacter rodentium. J Bacteriol 2005, 187:7009-7017.
Publish with Biomed Central and every scientist can read your work free of charge

"BioMed Central will be the most significant development for disseminating the results of biomedical research in our lifetime. "

Sir Paul Nurse, Cancer Research UK

Your research papers will be:

- available free of charge to the entire biomedical community

- peer reviewed and published immediately upon acceptance

- cited in PubMed and archived on PubMed Central

- yours - you keep the copyright
Biomedcentral 